\begin{tabular}{|l|l|l|}
\hline PUCRS & HUMANIDADES \\
\hline Ihttp://dx.doi.org/10.15448/2178-5694.2020.1.35319 & $\begin{array}{l}\text { Conversas \& Controvérsias, Porto Alegre, v. 7, n. 1, p. 1-11, jan.-jun. } 2020 \\
\text { e-ISSN: 2178-5694 }\end{array}$ \\
\hline
\end{tabular}

SEÇÃO: DOSSIÊ

\title{
Entre rupturas e continuidades: o percurso da legislação para adolescentes e jovens no Brasil
}

Between breaks and continuities: route of legislation for adolescents and youth in Brazil

Bruna Rossi Koerich ${ }^{1}$

orcid.org/0000-0001-9791-7808

koerich.bruna@gmail.com

\author{
Alex da Silva Vidal ${ }^{1}$ \\ orcid.org/0000-0002-0166-0698 \\ alexsvidal@terra.com.br
}

Recebido em: 14 ago. 2019

Aprovado em: 26 jun. 2020.

Publicado em: 17 set. 2020.
Resumo: O objetivo deste artigo é analisar quais as concepções de infância, adolescência e juventude que orientaram a execução de políticas e de ações públicas em diferentes momentos históricos do pais. Para isso, analisaremos os principais marcos legais voltados a essas parcelas da população. A análise do percurso histórico apontou para a permanência de discursos de intervenção estatal sobre a juventude vinculados à lógica da assistência social, uma constante em diferentes momentos históricos. Foi possivel constatar, também, que o deslocamento dessa população enquanto problema social para a compreensão de crianças e de adolescentes como sujeitos de direitos vem acompanhado de uma inscrição de ações na assistência social, sobretudo no tocante à execução das medidas socioeducativas, gerando confusões entre a garantia de direitos fundamentais e processos de responsabilização.

Palavras-chave: Direitos da criança e do adolescente. Políticas públicas para as juventudes.

Abstract: This article aims to analyze which are the conceptions of childhood, adolescence and youth oriented the execution of public policy in different historical moments of the country. For this, We will analyze the main legal frameworks for these portions of the population. The analysis of the historical course pointed to the permanence of discourses of state intervention on youth linked to the logic of social assistance, a constant in different historical moments. It was also found that the displacement of this population as a social problem for the understanding of children and adolescents as subjects of rights is accompanied by an inscription of actions in social assistance, especially regarding the implementation of socio-educational measures, generating confusion between the guarantee fundamental rights and accountability processes.

Keywords: Child and adolescent rights. Public policies for youths.

\section{Introdução}

Apesar de a preocupação com crianças, adolescentes e jovens no Brasil ter ganhado destaque nas últimas quatro décadas - tanto no campo acadêmico, como na execução de políticas públicas e projetos sociais - a temática existe no país desde os primeiros anos da República.

Lançar mão para a história das ações públicas voltadas para crianças, adolescentes e jovens no país e, sobretudo, buscar compreender quais as concepções de infância, adolescência e juventude orientaram essas intervenções, é um exercício necessário para um melhor entendimento de como são hoje executadas políticas públicas e projetos sociais.

Assim, buscamos aqui analisar os principais marcos legais voltados a essas parcelas da população para, posteriormente, tecer considerações sobre as concepções presentes nessas politicas na contemporaneidade. 
Esse artigo é baseado, por um lado, em duas pesquisas que deram origem às dissertações de mestrado dos autores. E, por outro, na atuação prática dos autores na execução de políticas públicas para a juventude.

Em termos metodológicos, as análises dos marcos legais foram feitas sob a luz da análise de conteúdo, sob o enfoque proposto por Bardin (2011), no sentido de investigar e categorizar o conteúdo encontrado a partir das relações entre as expressões possibilitadas pelo sistema linguistico e pelos aspectos mais gerais do contexto.

Nosso olhar está voltado para o discurso da legislação e como ela embasa a prática de identificação de uma parcela da população que está de alguma forma fora das normas estabelecidas como padrão, para poder utilizar mecanismos de controle e moralização.

No tocante às discussões sobre as concepções contemporâneas de adolescência e de juventude, podemos afirmar que trazemos sinteses de reflexões geradas pelo cotidiano de trabalho com esse público.

Escolhemos as quatro legislações principais que trataram o tema da infância, da adolescência e da juventude, como forma de nos deslocar no tempo: o Código de Menores de 1927, o Código de Menores de 1979, o Estatuto da Criança e do Adolescente de 1990, e o Estatuto da Juventude de 2013. Cada um desses marcos, produzidos em seus períodos históricos, representam as intenções do Estado brasileiro quanto à política para essas parcelas da população. Le Goff (2003) nos diz que a história recolhe sistematicamente, classificando e agrupando os fatos do passado, em função das necessidades atuais. Então, utilizamos a história como ferramenta para selecionar e agrupar rastros do passado, confrontando-os com o presente e refletindo sobre esse encontro.

Importante também dizer que entendemos o direito como uma das expressões sociais acerca de certas temáticas em cada periodo histórico. A retomada do percurso da legislação brasileira acerca dos adolescentes e dos jovens no Brasil aqui aparece como uma forma de compreender quais visões embasaram a construção da atuação estatal e social sobre esses agentes.
Longe de imaginar que essas visões foram estáticas nesses periodos e que representavam a compreensão de toda a população a esse respeito, a apresentação dos entendimentos hegemônicos acerca das crianças, dos adolescentes e dos jovens brasileiros é, na verdade, um recurso didático para a compreensão do marco legal de cada período. Acreditamos que a apresentação das mudanças e das rupturas ocorridas em cada uma das etapas que serão apresentadas constitui-se como prova da existência de disputas ideológicas envolvidas nessa temática.

\section{O período pré-códigos de menores}

A discussão acerca da adolescência é relativamente recente no País. Os primeiros textos legais que falam sobre essa parcela da população utilizam o termo menor como forma generalizante de abordar todos os sujeitos menores de 18 anos.

Logo após a independência do Brasil, em 1830. é criado o primeiro Código Criminal Brasileiro, que foi baseado nas Ordenações Filipinas, que estavam em vigor anteriormente. Neste novo código, não havia nada em especial para julgar a criança e o adolescente, apenas o fato de não se julgar criminosos os menores de 14 anos; entretanto, sem a inimputabilidade plena, pois, se o juiz entendesse que o réu agiu com discernimento, o menor de idade poderia ser mandado para casa de correção, onde tinha a possibilidade de ficar até os 17 anos. Importante ressaltar que, segundo Moreira (2011), nesse periodo crianças e jovens eram mantidos junto com os adultos para o cumprimento de suas penas. Data desse período, também, a consolidação de parcerias entre o Poder Público e o setor privado para o desenho das politicas para os menores de idade, que serão executadas especialmente por entidades beneficentes e religiosas.

Em 1890 é promulgado o Código Penal dos Estados Unidos do Brasil, durante o periodo da República. Nesse novo documento, em relação à criança e ao adolescente, as leis mudam um pouco. Até os nove anos se têm inimputabilidade plena e até os 14 anos se faz uma avaliação se a infração foi cometida com discernimento por parte 
do jovem, caso em que esse poderia ser mandado a um estabelecimento disciplinar industrial.

Com o código de 1890, vemos também alguma tentativa de inserir esse jovem na sociedade através do trabalho. A República que nasce no Brasil, de características positivistas, vê no trabatho uma via para a educação, a organização e a ocupação, distanciando as pessoas dos vícios e das libertinagens. Para as elites da época, o trabalho era um eixo essencial para uma boa moral e bons costumes. Sendo assim, o ócio e o vício estavam cada vez mais ligados à delinquência e ao crime, e era crescente a preocupação com a pobreza urbana. Nesse sentido, quem não tinha trabalho formal era criminalizado.

No final do século XIX, uma nova influência chega ao Brasil e cai como uma luva diante das intenções da elite: a criminologia, com o objetivo de compreender o criminoso e através desse conhecimento organizar estratégias de combate à criminalidade, servindo também como políticas de controle social:

As concepções da criminologia - que começava a se constituir como um campo de conhecimento com pretensões de cientificidade voltada para a compreensão da natureza do crime e do criminoso, mas que, em alguns momentos, também ambicionava ser um conhecimento mais amplo acerca da própria vida social - foram incorporadas com entusiasmo por grande parte da intelectualidade brasileira. (Alvarez 2002, 678)

Nesse sentido, o poder faz uso de saberes para se manter, assim como o saber ganha força através do poder e lhe dá forma "A justiça moderna passaria a investir na reintegração social do criminoso no seu aproveitamento e na sua docilidade" (Schuch 2009, 109).

No Brasil, a grande influência da criminologia vem da antropologia criminal oriunda do pensamento de Cesare Lombroso, para quem o crime possuia raizes biológicas, que poderiam ser identificadas a partir de estigmas anatômicos e da formação dos sujeitos, podendo, assim, o crime ser considerado e categorizado como um fenômeno natural, e o criminoso, como um primitivo e um doente (Alvarez 2002, 679). Para Lombroso, toda a criança já trazia embutido o germe da loucura moral e da delinquência.

Inspirada nessa perspectiva de aumento da intervenção estatal na sociedade para a garantia de segurança e em movimentos internacionais que reivindicavam o reconhecimento da condição distinta da criança e do adolescente em relação ao adulto, surge a necessidade de uma legislação especíica para esse público, nascendo, assim, o primeiro Código de Menores, em 1927.

\section{Código de Menores de 1927}

O Código de Menores é baseado em leis que já estavam sendo construidas desde o início da década de 1920. A primeira legislação específica para a infância e a adolescência no Brasil, claramente é voltada apenas para uma parcela dessa população, a "abandonada" ou a "delinquente". O Código de Menores de 1927, sob o discurso de se desenvolver medidas para a assistência e para a proteção da criança e do adolescente, cria uma série de artefatos legais para o controle e para a tentativa de reeducação.

Art. $1^{\circ}$ O menor, de um ou outro sexo, abando-
nado ou delinquente, que tiver menos de 18
annos de idade, será submettido pela autori-
dade competente ás medidas de assistencia e
protecção contidas neste Codigo. (Brasil 1927, 1)

O Código Mello Mattos², como também era chamado, reafirma que o menor delinquente, menor de quatorze anos, ficaria eximido de qualquer processo penal, enquanto o menor de $18 \mathrm{e}$ maior de 14 anos ficariam submetido a processo especial estabelecido por este Código:

Art. 69. O menor indigitado autor ou cumplice de facto qualificado crime ou Contravenção, que contar mais de 14 annos e menos de 18 . será submettido a processo especial, tomando, ao mesmo tempo, a autoridade competente as precisas informações, a respeito do estado physico, mental e moral delle, e da situação social, moral e economica dos paes, tutor ou pessoa incumbida de sua guarda.

(...)

\footnotetext{
2 O Dr. José Cândido de Albuquerque Mello Mattos, nascido aos 19 de março de 1864 na cidade de Salvador/BA, foi o primeiro Juiz da Infância e da Juventude do Brasil. Ele foi nomeado em 02/02/1924.
} 
$\S 2^{\circ}$ Si o menor não fôr abandonado, nem pervertido, nem estiver em perigo de o ser, nem precisar do tratamento especial, a autoridade o recolherá a uma escola de reforma pelo prazo de um a cinco annos.

$\S 3^{\circ} \mathrm{Si}$ o menor fôr abandonado, pervertido, ou estiver em perigo de o ser, a autoridade o internará em uma escola de reforma, por todo o tempo necessario á sua educação, que poderá ser de tres annos, no minimo e de sete annos, no máximo. (Brasil 1927,10)

Mesmo se o jovem fosse absolvido, o juiz poderia determinar o recolhimento do jovem para uma instituição de educação, assim como ter a sua liberdade vigiada ou obter da familia o compromisso quanto ao seu bom comportamento. O ato do jovem que infringiu a lei fica em segundo plano. Podemos notar que, o que determina a ação que o juiz irá tomar, e o tempo em que o jovem ficará em uma instituição de reforma, está de acordo com as condições sociais e econômicas em que ele está inserido. O que se avalia é o ambiente social em que ele vive, o que é julgado é a pobreza, e não a infração cometida. Os pais, assim como as crianças, são condenados como culpados por viverem em condições miseráveis, como se isso fosse de sua inteira e exclusiva responsabilidade.

Outro destaque é a mudança na terminologia que o primeiro código traz. Enquanto nas leis anteriores, se falavam de penas para crianças e adolescentes, como no caso dos adultos, com o Código de Menores se passa a utilizar o termo medidas. Esse novo termo passa a distinguir a forma que se deveriam tratar os menores que infringiram a lei dos adultos. Ao mesmo tempo, o termo medida também aproxima esse mesmo "menor", muitas vezes envolvido com a criminalidade, de outros em situação de abandono ou vulnerabilidade.

A principal aposta para a assistência e a proteção das crianças e dos adolescentes definida pelo código é a institucionalização. Identificamos nesse Código uma classificação dessas crianças e adolescentes em seis categorias: 1) o "pervertido", que sofre de alguma "deficiência" mental ou física; 2) a criança ou adolescente que vive em boas condições sociais, não é "pervertido", mas cometeu algum ato contra a lei; 3) o "pervertido" ou delinquente devido ao meio; 4) aquele que não é pervertido ou delinquente, mas está em perigo de o ser (ou seja, vive em condições sociais moralmente suspeitas); 5) o vadio (ganha a vida nas ruas); e 6) o menor abandonado (que por esse motivo se encontra em uma situação de risco).

A partir dessa classificação, a cada uma destas categorias se determina, também, uma tecnologia de tratamento: aos delinquentes e pervertidos, a instituição de reforma, aos abandonados e àqueles em perigo de se tornar delinquentes, a instituição de proteção; e àqueles com alguma deficiência, um tratamento especializado segundo suas necessidades (instituições psiquiátricas). Ou seja, o confinamento em uma instituição total é visto como a grande resposta de controle dessa população. Mas a Lei, embora mencione essa classificação, centraliza no juiz a decisão de quais os mecanismos serão utilizados em cada caso. 0 fato é que os que cometeram alguma infração e os abandonados ou a perigo de virarem delinquentes acabaram misturados e vistos da mesma forma, como constituindo um único grupo.

A intenção do código não está concentrada na pena ou na punição e sim na disciplina, nas técnicas de formar e submeter o sujeito às regras, na perspectiva da regeneração, da reabilitação, da assistência e, também, da prevenção. Para cumprir os seus objetivos de salvar os jovens órfãos, abandonados e criminosos da delinquência, e de se preservar de ter que lidar no futuro com um adulto criminoso perigoso, o Estado brasileiro tinha à mão diversos mecanismos para mantê-los sob controle, como a tutela, a guarda, a vigilância, a reeducação, a preservação, a moralização e o confinamento (Moreira 2011, 132).

Uma alternativa à institucionalização é a liberdade vigiada, uma medida de segurança que tem como objetivo a gradual "reabilitação" do indivíduo ao seu meio social. No entanto ele permanece sob vigilância por uma pessoa indicada pelo juiz de menores. Essa pessoa tem a responsabilidade de se manter perto da criança para assegurar sua "recuperação". A liberdade vigiada vem da liberação condicional, da Lei n. ${ }^{\circ} 4242$ de 1921, que era um benefício ou uma progressão e não realmente uma alternativa à institucionalização (Ortegal 2011). Ou seja, essa é a origem do meio aberto no Brasil. 
O Código de Menores sobreviveu por mais de 60 anos no Brasil, tendo sofrido algumas alterações com a promulgação do novo Código de Menores, em 1979.

\section{Código de Menores de 1979}

No Código de Menores de 1979, o objetivo continua sendo o da proteção e da assistência e, seguindo a antiga lei, ele não abrange todas as crianças e adolescentes, ou seja, ele será aplicado apenas às crianças e adolescentes consideradas em situação irregular.

Art. $1^{\circ}$. Este Código dispõe sobre assistência, proteção e vigilância a menores:

I - até dezoito anos de idade, que se encontrem em situação Irregular:

II - entre dezoito e vinte um anos de idade, nos casos expressos em lei.

(Brasil 1979, 1)

Assim, o novo Código, junta o que antes eram os adolescentes delinquentes, abandonados ou pervertidos em uma única categoria: os em situação irregular. Abaixo podemos ver quem eram esses:

Art. $2^{\circ}$. Para os efeitos deste Código, considera-se em situação irregular o menor:

I - privado de condições essenciais à sua subsistência, saúde e instrução obrigatória, ainda que eventualmente, em razão de:

a) falta, ação ou omissão dos pais ou responsável;

b) manifesta impossibilidade dos pais ou responsável para provê-las:

II - vítima de maus tratos ou castigos imoderados impostos pelos pais ou responsável;

III - em perigo moral, devido a:

a) encontrar-se, de modo habitual, em ambiente contrário aos bons costumes;

b) exploração em atividade contrária aos bons costumes;

IV - privado de representação ou assistência legal, pela falta eventual dos pais ou responsável;

$\checkmark$ - Com desvio de conduta, em virtude de grave inadaptação familiar ou comunitária;

VI - autor de infração penal. (Brasil 1979, 1)

Ou seja, o novo Código de Menores mistura todas as categorias que o Código antigo havia criado e os entende como em situação irregular. Sendo assim, o adolescente que não tem condições de moradia é visto da mesma forma que o adolescente que quebra a lei. Abaixo podemos ver as medidas que podem ser aplicadas a essa população:

$$
\begin{aligned}
& \text { Art. 14. São medidas aplicáveis ao menor pela } \\
& \text { autoridade judiciária: } \\
& \text { I - advertência; } \\
& \text { II - entrega aos pais ou responsável, ou a pessoa } \\
& \text { idônea, mediante termo e responsabilidade; } \\
& \text { III - colocação em lar substituto; } \\
& \text { IV - imposição do regime de liberdade assistida; } \\
& \text { V - colocação em casa de semiliberdade; } \\
& \text { VI - internação em estabelecimento educacio- } \\
& \text { nal, ocupacional, psicopedagógico, hospitalar, } \\
& \text { psiquiátrico ou outro adequado. (Brasil 1979, 3) }
\end{aligned}
$$

Vale ressaltar que todas essas medidas judiciais poderiam ser destinadas a todos os jovens em situação irregular, tenham ou não cometido algum ato infracional à lei. A questão é, assim como no antigo Código de 1927, retirá-los de um contexto de moral duvidosa ou abandono e colocá-los em um local onde possam ser educados e aprender uma profissão; tirá-los da circulação social com a finalidade de prevenção, de assegurar a segurança pública e coletiva. Na prática, se constata que continua a prática de criminalização da pobreza e se trata a infração como uma doença, individualizando a medida e eximindo qualquer responsabilidade da sociedade.

Vemos no novo Código também uma ampliação de instrumentos alternativos à institucionalização. Passa-se a ter igualmente a opção de advertência do Juiz e, também, a semiliberdade como novos instrumentos para serem aplicados. Para o meio aberto, temos na prática, apenas uma mudança de termos, a liberdade vigiada se torna liberdade assistida, assim como temos hoje. Ou seja, a aposta segue sendo na institucionalização.

Interessante que, assim como no Código de 1927, o novo Código também não fala de responsabilização e nem de punição. Se utiliza o discurso de proteção e de assistência como forma de tutelar e de controlar essa parcela da população. 


\section{Estatuto da Criança e do Adolescente de 1990}

O Estatuto da Criança e do Adolescente (ECA) é construído no movimento de redemocratização do Pais, com o fim da Ditadura Civil-Militar, na esteira da Constituição de 1988 e com a pressão de grande parte da sociedade civil juntamente com instituições religiosas que atentavam, principalmente, para a problemática dos "meninos de rua" e do trabalho infantil.

Segundo Patrice Schuch (2009), os códigos de menores anteriores eram vistos por ativistas e analistas da área de direitos humanos como estigmatizantes das crianças e dos adolescentes pobres, a quem essas legislações eram claramente direcionadas. Já o ECA é construído com uma intenção diferente:

A nova legislação, ao contrário, integra o processo de disseminação global dos chamados "direitos das crianças" que, do bojo da imergente retórica universalista dos "direitos humanos", visa ampliar a noção de cidadania para todas as crianças e adolescentes, tornando-as sujeitos de direitos. Aparece em um contexto de democratização da sociedade brasileira, ampliando a participação da familia e da comunidade nas politicas de atenção dos direitos da criança e adolescente através da orientação para a implantação de instâncias de participação federal, estatais e municipais. (Schuch 2009, 129)

O Estatuto tem sua primeira inovação ao ser direcionado a toda população infantojuvenil, diferente dos outros códigos que eram voltados apenas aos que estavam em "situação irregular". Outra modificação é considerar todos os sujeitos, sejam na infância e na juventude, pessoas com plenos direitos:

Art. $3^{\circ} \mathrm{A}$ criança e o adolescente gozam de todos os direitos fundamentais inerentes à pessoa humana, sem prejuizo da proteção integral de que trata esta Lei, assegurando- Lhes, por lei ou por outros meios, todas as oportunidades e facilidades, a fim de lhes facultar o desenvolvimento físico, mental, moral, espiritual e social, em condições de liberdade e de dignidade. (Brasil 1990, 1)

O Estatuto define como criança todo ser humano até 12 anos incompletos e adolescentes até 18 anos incompletos. As crianças são penalmente inimputáveis e penalmente irresponsáveis. As crianças só podem receber do juizado medidas de proteção. Já os adolescentes, são penalmente inimputáveis; no entanto, são penalmente responsáveis. Ou seja, respondem penalmente de acordo com a legislação especifica a ações análogas aos crimes no direito penal (Méndez 2006, 12). Para Méndez, essa responsabilidade penal dos adolescentes é um componente central de seu direito para viver uma cidadania plena.

Podemos conceituar ato infracional como toda conduta, praticada por criança ou adolescente, definida como crime ou contravenção pelo Código Penal Brasileiro. Para a configuração do ato infracional é necessária a presença de indícios suficientes da autoria e da materialidade do fato. Ainda, como prevê o Estatuto, são asseguradas aos adolescentes todas as garantias processuais tais como o direito ao contraditório, a ampla defesa, a defesa técnica por advogado e o devido processo legal. Sem essas garantias, medida alguma poderá ser concedida ao adolescente autor de ato infracional, sob pena de nulidade processual (Veronese e Lima 2009, 33, 34). Essa talvez seja a maior mudança que o ECA propõe. Ao enxergar na criança e no adolescente sujeitos de direitos, eles têm meios de se defender e direito de falar, e as instituições, o dever de ouvi-los.

Outra grande mudança que o ECA proporcionou foi a separação entre os adolescentes que cumpriam medida de internação e os que viviam em abandono. Essa separação já existia no Código de Mello Matos, mas ela não era clara, permitindo diferentes interpretações. No Código de Menores de 1979, há uma junção das duas categorias, que é desfeita com o ECA:

A grande novidade do ECA é distinguir com precisão quase cirúrgica, a Medida de Proteção da Medida Socioeducativa. No Código de Menores, uma mesma medida se aplicava a todos os adolescentes, pois tudo era considerado proteção. (Raniere 2014, 48)

Para os adolescentes que foram julgados culpados por um ato infracional, o ECA prevê medidas socioeducativas e medidas de proteção. A institucionalização segue sendo uma das grandes alternativas para lidar com adolescentes 
em conflito com a lei e, embora de forma mais limitada, o Estatuto admite a medida de privação de liberdade apenas em casos de reiteração e de violência contra pessoa e durante o tempo máximo de três anos. No entanto, há uma clara tentativa de ampliar e reforçar o meio aberto que ganha novos instrumentos. Existem quatro possibilidades de medidas: liberdade assistida (LA.); prestação de serviço à comunidade (PSC); e reparação do dano e advertência (Brasil 1990, 54)

Segundo Saraiva $(2006,65)$, apesar de sua finalidade pedagógica, a medida socioeducativa não deixa de possuir uma natureza retributiva, na situação em que somente ao autor de ato infracional se reconhece a aplicação de sanção. Tem força de coercibilidade, sendo, pois, imposta ao adolescente, ou seja, existe também um caráter punitivo.

\section{O Estatuto da Juventude de 2013}

Apesar de já no ECA haver o reconhecimento de jovens como sujeitos prioritários, é somente no ano de 2010 que temos o termo "juventude" incorporado expressamente na Constituição Federal, por meio da Emenda Constitucional n. ${ }^{\circ}$ 65, que define, também, o Estatuto da Juventude como instrumento capaz de regular os direitos dos jovens e articular as diferentes esferas do poder público na execução de políticas à juventude.

Em termos de agenda política, a temática da juventude aparece com ênfase já na década de 1990 a partir dos "esforços de pesquisadores, organismos internacionais, movimentos juvenis e gestores municipais que enfatizavam a singularidade da experiência social desta geração de jovens" (Brasil 2006). Contudo, como boa parte das discussões sobre a temática nesse periodo concentraram esforços na construção do Estatuto da Criança e do Adolescente, as ações e políticas voltadas para a juventude se restringiam ao atendimento do jovem de até 18 anos. Não obstante o considerável leque de ações orientadas ao público juvenil, a preocupação central é a de prevenir o envolvimento de jovens na criminalidade urbana por meio de atividades de elevação da escolaridade e a inserção no mercado de trabalho.

A resposta governamental a essa situação tem se dado por meio de políticas de valorização da formação educacional básica, por um lado, e por programas destinados a promover as primeiras experiências no mundo do trabalho, por outro lado. No entanto, os investimentos na educação básica, indiscutivelmente de grande importância, não têm se mostrado suficientes diante da atual dinâmica do mercado de trabalho (Belluzzo e Victorino 2004, 14).

Em 2005 é criada a Secretaria Nacional da Juventude (SNJ), como resultado de um Grupo de Trabalho Interministerial que reuniu 19 ministérios com o intuito de construir uma Política Nacional de Juventude. No mesmo ano é criado o Conselho Nacional de Juventude (CONJUVE) como espaço de diálogo sobre a temática também com a sociedade civil, formada por representantes do poder público, de movimentos sociais e de entidades não governamentais.

Em 2013 é promulgado, finalmente, o principal marco legal sobre juventude no País. São considerados jovens, no Estatuto, pessoas que possuam entre 15 e 29 anos. Tendo em vista a intersecção etária existente entre adolescentes e jovens, o Estatuto deixa explícito a preponderância do ECA como marco para adolescentes entre 15 e 18 anos:
$1^{\circ}$ Para os efeitos desta Lei, são consideradas jovens as pessoas com idade entre 15 (quinze) e 29 (vinte e nove) anos de idade.
$\S 2^{\circ}$ Aos adolescentes com idade entre 15 (quin- ze) e 18 (dezoito) anos aplica-se a Lei no 8.069. de 13 de julho de 1990 - Estatuto da Criança e do Adolescente, e, excepcionalmente, este Estatuto, quando não conflitar com as normas de proteção integral do adolescente. (Brasil 2013, 1)

Em termos de concepção, o Estatuto da Juventude (EJ) reforça o argumento de que jovens são sujeitos de direitos e, por isso, as políticas públicas devem garantir o bem-estar desses sujeitos, respeitando a sua autonomia e focando em ações que estimulem a sua emancipação.

Levando em consideração o contexto em que foi redigido e promulgado, um dos pontos centrais do EJ passa a ser a defesa da participação juvenil nos processos de desenho e execução das políticas públicas voltadas para esse setor.

O Estatuto da Juventude apresenta 11 direitos fundamentais à juventude brasileira: 1) direito 
à cidadania, à participação social e política e à representação juvenil; 2) direito à educação; 3) direito à profissionalização, ao trabalho e à renda; 4) direito à diversidade e à igualdade; 5) direito à saúde; 6) direito à cultura; 7) direito à comunicação e à liberdade de expressão; 8) direito ao desporto e ao lazer; 9) direito ao território e à mobilidade; 10) direito à sustentabilidade e ao meio ambiente; e 11) direito à segurança pública e o acesso à justiça. Cada um desses direitos fundamentais é apresentado em sessão específica. E em basicamente todas as sessões, é enunciada a necessidade da participação juvenil no desenho e na elaboração das ações voltadas à garantia de cada um desses direitos especificamente.

Na sessão dedicada ao direito à educação, por exemplo, não apenas são assegurados os direitos de acesso e de permanência em instituições de ensino, mas também é prevista a participação juvenil efetiva nos espaços de deliberação das instituições de Ensino, conforme apresentado no Artigo 12 do EJ:

Art. 12. É garantida a participação efetiva do segmento juvenil, respeitada sua liberdade de organização, nos conselhos e instâncias deliberativas de gestão democrática das escolas e universidades. (Brasil 2013, 2)

O envolvimento do segmento juvenil também é previsto em outras seções, afirmando que a participação juvenilé o grande eixo transversal que articula os 11 direitos fundamentais previstos no Estatuto.

São criados, assim, instrumentos de controle social, que contam com a participação de jovens, no intuito de construir políticas não apenas para, mas também, de e com as juventudes (Castro e Abramovay 2002).

Muitas foram as politicas públicas e os projetos sociais desenvolvidos para a juventude após esse periodo, voltados, enfaticamente, para a ampliação da escolaridade e a qualificação profissional como formas de prevenção à violência e À mortalidade juvenil. Contudo, ainda faltam sistematizações dessas ações e pesquisas que consigam compreender quais são as principais concepções de juventude mobilizadas em cada uma delas, e demonstrar, a partir de evidências, quais os seus impactos e efeitos.
Um cuidado a ser tomado, nesse sentido, é o de garantir processos de participação juvenil também nas políticas voltadas para a qualificação profissional como ferramenta de prevenção à violência e à mortalidade juvenil. Isso porque ao público juvenil que frequentemente acessa essas politicas (jovens com baixa escolaridade e moradores das periferias urbanas), poucos são os espaços de engajamento social e participação política. Dessa forma, corre-se o risco de dividir o público do Estatuto da Juventude em dois grandes grupos: aos jovens com melhores condições de vida é reservado o direito à participação social, enquanto àqueles a que se destinam as políticas de prevenção à violência, a participação social torna-se desnecessária.

\section{Reflexões finais}

No final do século XIX e durante o século XX, o "antigo medo das elites diante dos escravos será substituido pela grande inquietação em face da presença da pobreza urbana nas principais metrópoles do país" (Alvarez 2002, 693). A jovem República e sua elite tiveram que redobrar esforços para legitimar o novo regime e desenvolver processos de controle social, que foram atrelados ao trabalho, à familia e aos bons costumes, com o objetivo de ordenar as classes populares no sistema recém-instaurado (Alvarez 2002, 18). Os que não conseguiam ou não queriam trabalho fixo, acabavam estigmatizados como vadios e, portanto, criminosos. O sistema de justiça, incluindo a polícia e, também, os órgãos de saúde, tinha como função identificar e controlar essa população excedente das grandes e médias cidades.

O medo e a tentativa de controle das classes baixas levaram a elite a utilizar, transformar e desenvolver diversas ferramentas para atingir seus objetivos. A normatização (ou seja, a utilização da justiça como estratégia para reforçar a norma) se tornou crescente. A partir disso, os "desfavorecidos" foram transformados em classes "perigosas", e a pobreza, a falta de condições materiais e sociais de se ingressar dentro da norma, foi criminalizada. A justiça, a assistência e a saúde se tornam espaços, principalmente, de controle.

Para Foucault (2012), esse esforço por parte da 
elite em moralizar o povo, no sentido do trabalho e da ordem, tem a ver com uma mudança nos meios de produção. É uma tentativa da elite de resguardar suas riquezas, já que, com a inserção do trabalho assalariado e das indústrias, os instrumentos de trabalho, assim como a matéria-prima para a produção dos produtos, ficam nas mãos dos empregados. A moralização do povo tem o objetivo de que eles vendam seu trabalho por um salário, mas que também não se sintam propensos a roubar as mercadorias ou danificar máquinas.

As crianças e os adolescentes caem nesse emaranhado de diversas formas. Neste trabalho, nos detivemos mais especificamente no espaço da justiça para fazer uma análise histórica da categoria dos adolescentes em conflito com a lei. Observamos que, sob a justificativa da proteção, da educação e da assistência, as crianças e os jovens são vigiados e separados de suas famílias e do meio social. Sob o capuz de boas intenções, se cometeram grandes atrocidades:

A historiografia sociojuridica da infância e adolescência revela que esses grupos vulneráveis sempre foram alvos de toda forma de negligência, violência e opressão. Ao normatizar as relações sociais, as leis menoristas serviram para escamotear verdadeiras crueldades nos tratamentos dispensados à infância e juventude, em que o ser adulto sempre foi, nessa relação, aquele que tudo podia e a voz da autoridade. (Veronese e Lima 2009, 41-42)

Durante todo o período estudado, foram lançados e reforçados diversos discursos sobre os jovens da periferia, construiu-se o estigma de "infrator", que é associado à estética dos jovens pobres das grandes cidades, causando um efeito duplo. Esse efeito duplo é a criação dos perigosos e dos perigosos em potencial, colocando todos os jovens da periferia em suspeição.

O Estatuto da Criança e do Adolescente tenta romper com a visão desses jovens como incapacitados e os coloca em uma condição nova até o momento - a de cidadão. No entanto, muitas práticas permanecem, não apenas agindo de forma tutelar e violenta, como também reproduzindo o estigma e os discursos que o permeiam. A principal pergunta aqui é: de que forma, que instrumentos e que discursos são utilizados para que as práticas tutelares permaneçam?

Tanto Méndez quanto Saraiva se mostram preocupados com algumas interpretações que consideram equivocadas do Estatuto, que acabam por abrir espaço para a aplicação de um direito com caracteristicas de tutela, como no antigo Código de Menores: "Práticas norteadas pela antiga Doutrina da Situação Irregular permanecem em vigor, travestidas de operacionalidade do Estatuto da Criança e do Adolescente, a produzir um neomenorismo" (Saraiva 2006, 55). Essas práticas perigosas, são as que vêm da "boa intenção" dos operadores do sistema de justiça, que acabam atropelando direitos pela vontade de assegurar aquilo que imaginam ser o melhor para essas crianças e adolescentes. A ideia de uma medida que proteja e eduque sempre foi utilizada como forma de tutelar.

Mesmo que a doutrina de proteção integral pregue o respeito dos jovens enquanto sujeitos de direitos, autores como Liana de Paula (2015) defendem que a predominância da intervenção assistencial em relação a esses sujeitos acaba colocando-se em oposição à inscrição de cidadania plena.

(...) a aproximação entre política de assistência social e execução de medidas socioeducativas recoloca a associação entre pobreza e criminalidade, reiterando sua permanência enquanto chave explicativa dos discursos e fonte de legitimidade das intervenções práticas. (Paula 2015, 40)

Nesse sentido, apesar de considerados como sujeitos de direitos, os jovens aparecem - no contexto tutelar que por vezes recai a assistência como vítimas de uma vulnerabilidade social que os coloca em riscos. Essa lógica justifica, com frequência, o envolvimento em práticas infracionais como consequência de uma trajetória de privação de direitos e inserção em contextos vulneráveis.

Essas abordagens receberam importantes críticas dentro dos estudos sobre juventudes e violências, no sentido de não explicar o envolvimento infracional de jovens não afetados por fatores de vulnerabilidade com a criminalidade e por potencializar uma perspectiva vitimizadora da juventude. 
(...) Essa perspectiva tende a privilegiar a relação entre juventude e violência de um enfoque predominantemente vitimizador, no sentido de que é na condição de vitimas das condições sociais de existência que esses jovens se encontram expostos, com maior frequência, a situações de violência, seja no âmbito doméstico, na convivência próxima com o tráfico de drogas, nos confrontos com a polícia etc. Porém, essa relação também pode analisada a partir do protagonismo dos jovens enquanto agentes de duas próprias trajetórias de vida, considerando-se também as motivações subjetivas e as interações positivas e negativas nos diversos âmbitos de sociabilidade (familia, amigos, colegas de escola e de trabalho, vizinhança) que condicionam as ações. (Pimenta 2014, 271)

Em relação ao Estatuto da Criança e do Adolescente, entendido como o grande marco jurídico que regulamenta os adolescentes como sujeitos de direitos, podemos afirmar que é bastante sucinto em relação às medidas socioeducativas, sugerindo que sua principal preocupação foi a de diferenciar os adolescentes "delinquentes" dos adolescentes com direitos violados.

Sobre essa separação, Patrice Schuch (2009) chama atenção para a tensão existente entre a assistência e a repressão, uma dificuldade de se afirmar se os adolescentes eram as vítimas ou os algozes, devido a essa junção que colocava os adolescentes que haviam cometido ato infracional com os em abandono. A partir do ECA, a autora afirma que há um refinamento na capacidade de classificação, entre os "perigosos" e os "em perigo" tornando menos ambíguo o trabalho de assistência e repressão.

É a partir do ECA que há a necessidade de distinção entre programas para os adolescentes a quem se atribua autoria de ato infracional - as medidas sócio- educativas - e as crianças e adolescentes em situação de risco pessoal e social - as medidas protetivas. (Schuch 2009, 129)

De toda forma, ao dedicar pouco espaço para o debate acerca do sistema de justiça juvenil, o ECA acaba prevendo para o adolescente autor ato de infracional, assim como os demais, a garantia dos direitos fundamentais. O debate sobre o processo de responsabilização acaba, portanto, ficando evasivo, fazendo com que a execução das medidas seja heterogênea e dependa do espaço de gestão e execução de cada medida.

Apesar de ser uma legislação voltada para todas as crianças e adolescentes brasileiros, o ECA acabou consolidando-se, no entendimento popular e no discurso midiático, como marco legal orientado para adolescentes que cometeram ato infracional. Dessa forma, podemos afirmar que as três principais legislações para crianças e adolescentes promulgadas ao longo da história do País, acabaram concentrando esforços em versar sobre adolescentes em situações "irregulares" ou contrárias às expectativas sociais.

Já o Estatuto da Juventude, reforçando a noção de jovens como sujeitos de direitos acaba por consolidar-se como uma legislação mais generalista, voltada ao conjunto de jovens brasileiros. Vemos que grande parte do texto do Estatuto da Juventude é dedicado à apresentação do Sistema Nacional da Juventude e, principalmente, dos espaços de participação política e de controle social por parte da juventude. De certa forma, podemos afirmar que os jovens integrantes de partidos ou organizações sociais são o principal objeto do Estatuto da Juventude, permitindo, assim, que observemos um deslocamento do sujeito central dos marcos legais do "jovem problema" para o "jovem engajado".

Contudo, os resquícios do menorismo podem ser encontrados, também, no tocante à juventude protegida pelo Estatuto da Juventude. Isso porque, na prática, o que percebemos é a existência de políticas de qualificação profissional voltadas para as juventudes das periferias urbanas como forma de prevenir os índices de criminalidade e de letalidade juvenil, sem que sejam criados espaços de participação juvenil para os jovens que acessam este "tipo" de política. Assim, enquanto a alguns jovens é assegurado o direito da participação social, a outros, a preocupação é a de garantir o seu não envolvimento com as redes criminais locais.

De forma geral, podemos observar a convivência de diferentes concepções de adolescência e juventude na contemporaneidade, tanto nos marcos legais que regem hoje essas parcelas da população, como nas ações e políticas voltadas para esses setores. Sendo possivel, dessa forma, afirmarmos 
que o percurso legal das ações voltadas para adolescentes ejovens no país é marcado por processos tanto de rupturas, como de continuidades.

\section{Referências}

Abramovay, M., M. G. Castro, L. C. Pinheiro, F. S. Lima \& C. C. Martinelli. 2002. Juventude violência e vulnerabilidade social na América Latina: Desafios para políticas públicas. Brasilia: Unesco/BID

Alvarez, Marcos César. 2002. "A criminologia no Brasil ou Como tratar Desigualmente os Desiguais". Dados 45, n.4: pp.677-704 https://doi.org/10.1590/So01152582002000400005

Bardin, Laurence. 2011. Análise de conteúdo. São Paulo: Edições 70

Brasil. 1927. "Decreto n 17.943-A/1927". Diário Oficial da União (12 de outubro de 1927) http://Www.planalto. gov.br/ccivil_03/decreto/1910-1929/D17943A.htm

Brasil. 1979. "Decreto Lei No 6.697 de 10 de outubro de 1979". Diário Oficial da União (10 de outubro de 1979). http://Www. planalto.gov.br/ccivil_03/leis/1970-1979/L6697.htm

Brasil. 1990. "Lei n. 8.069/199o". Diário Oficial da União, (16 Julho 1990) http://www.planalto.gov.br/ccivil_03/ leis/1970-1979/L6697.htm.

Brasil. 2013. "Lei n’ 12 852/2013. Diário Oficial da União (06 Agosto 2013). http://Www planalto.gov.br/ccivil_03/ leis/L8069.htm\#art267.

Foucault, Michel. 2012. Microfísica do Poder. São Paulo: Graal.

Foucault, Michel. 2010. Vigiar e Punir: nascimento da prisão. Petrópolis: Vozes.

Koerich, Bruna Rossi. 2018. "Entre trajetórias, desejos e (im)possibilidades: projetos de futuro na socioeducação de meio aberto". Dissertação de Mestrado. Pontificia Universidade Católica do Rio Grande do Sul.

Le Goff, Jaques. 2003. História e Memória. Tradução de Bernardo Leitão. Campinas: Editora Unicamp.

Malfitano, Ana Paula Serrata, Adorno, Rubens de Camargo Ferreira. 2006 "Infância, juventude e vivências nas ruas: entre o imaginário da instituição e do direito". Imaginario 12, n.12: 15-33.

Martins, P. O., Trindade, Z. A., Almeida, A. M. O. 2003. "O Ter e o Ser: Representações Sociais da Adolescência entre Adolescentes de Inserção Urbana e Rural". Psicologia: Reflexão e Crítica 16, n.3: 555-568.

Menandro, Maria Cristina Smith, Trindade, Zeidi Araújo, Almeida, Angela Maria de Oliveira. 2003. "Representações sociais da adolescência/juventude a partir de textos jornalisticos (1968-1974 e 1996-2002)". Arq. bras. psicol. 55, n.1: 43-55.
Méndez, Emílio Garcia. 2015. "A Criança E Seus Direitos Na América Latina: Quando o Passado Ameaça o Futuro". In Socioeducação: Fundamentos e Práticas. organizado por Carmem Craidy e Karine Szuchman, 28:38. Porto Alegre: Evangraf.

Mendez, Emilio Garcia. 2000. Por uma reflexão sobre o arbitrio e o garantismo na jurisdição sócio-educativa. Buenos Aires - Belo Horizonte.

Ortegal, Leonardo Rodrigues de Oliveira. 2011. "A medida socioeducativa de liberdade assistida: fundamentos e contexto atual". Dissertação de Mestrado. Universidade de Brasilia,

Paula, Liana de. 2015 "Da questão do menor à garantia de direitos: discursos e práticas sobre o envolvimento de adolescentes com a criminalidade urbana". Civitas v. 15, n. 1 (jan-mar): 27-43.

Pimenta, Melissa de Mattos. 2014."Juventude e Violência" In Crime, polícia e justiça no Brasil, organizado por Renato Sérgio de Lima, José Luiz Ratton e, Rodrigo Ghiringhelli de Azevedo, 265:276. São Paulo: Context.

Saraiva, João Batista Costa. 2006. Compêndio de direito penal juvenil: adolescente e ato infracional. Porto Alegre, Livraria do Advogado.

Schuch, Patrice. 2009. Práticas de justiça: antropologia dos modos de governo da infância e juventude no contexto pós-ECA. Porto Alegre: Editora da UFRGS, Ti k l

Verognse, Josiane R., Fernanda da Silva Lima. 2009 "O Sistema Nacional de Atendimento Socioeducativo (Sinase) - breves considerações". Revista Brasileira Adolescência e Conflitualidade, n. 1: 29-46.

Vidal, Alex da Silva. 2014. Adolescente em conflito com a lei: um estudo sobre estigma. Dissertação de Mestrado. Universidade Federal do Rio Grande do Sul.

\section{Bruna Rossi Koerich}

Doutoranda em Sociologia da Universidade Federal do Rio Grande do Sul (Ufrgs), em Porto Alegre, RS, Brasil. Bolsista Capes.

\section{Alex da Silva Vidal}

Doutorando em Educação da Universidade Federal do Rio Grande do Sul (Ufrgs), em Porto Alegre, RS, Brasil. Bolsista Capes. 